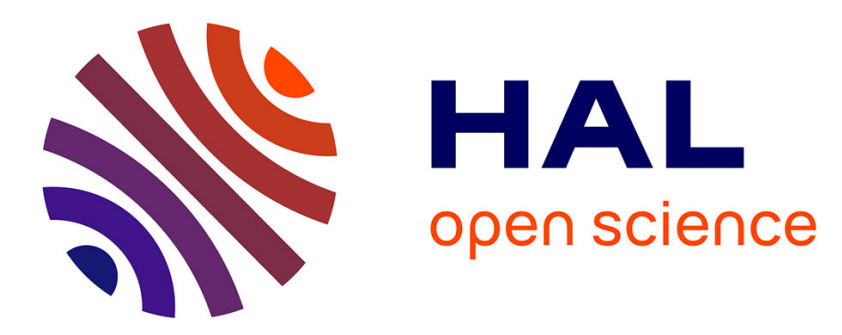

\title{
Organic doped diode rectifier based on parylene-electronic beam lithography process for radio frequency applications
}

Khaoula Ferchichi, Sébastien Pecqueur, David Guerin, Ramzi Bourguiga, Kamal Lmimouni

\section{To cite this version:}

Khaoula Ferchichi, Sébastien Pecqueur, David Guerin, Ramzi Bourguiga, Kamal Lmimouni. Organic doped diode rectifier based on parylene-electronic beam lithography process for radio frequency applications. Organic Electronics, 2021, 97, pp.106266. 10.1016/j.orgel.2021.106266 . hal-03279691

\section{HAL Id: hal-03279691 \\ https://hal.science/hal-03279691}

Submitted on 6 Jul 2021

HAL is a multi-disciplinary open access archive for the deposit and dissemination of scientific research documents, whether they are published or not. The documents may come from teaching and research institutions in France or abroad, or from public or private research centers.
L'archive ouverte pluridisciplinaire HAL, est destinée au dépôt et à la diffusion de documents scientifiques de niveau recherche, publiés ou non, émanant des établissements d'enseignement et de recherche français ou étrangers, des laboratoires publics ou privés. 


\section{Organic doped diode rectifier based on Parylene- electronic beam lithogrpahy process for Radio frequency applications}

Khaoula Ferchichi $^{*}{ }^{(1,2)}$, Sebastien Pecqueur ${ }^{(1)}$, David Guerin ${ }^{(1)}$, Ramzi Bourguiga ${ }^{(2)}$, Kamal Lmimouni $^{(1)}$

(1) Univ. Lille, CNRS, Centrale Lille, Univ. Polytechnique Hauts-de-France, UMR 8520 IEMN - Institut d'Electronique de Microélectronique et de Nanotechnologie, F-59000 Lille, France

(2) Laboratoire Physique des Matériaux, Structures et Propriétés Groupe Physique des Composants et Dispositifs Nanométriques, Facultés des sciences de Bizerte, Université de Carthage, 7021 Jarzouna-Bizerte, Tunisie.

Corresponding author*: khaoula.ferchichi@univ-lille.fr

\section{Abstract}

We have adapted a "peel-off" process to structure stacked organic semiconductors (conducting polymers or small molecules) and metal layers for diode microfabrication. The fabricated devices are organic diode rectifier in a coplanar waveguide structure. Unlike conventional lithographic process, this technique does not lead to destroy organic active layers since it does not involve harsh developer or any non-orthogonal solvent that alter the functionality of subsequentially deposited materials.

This process also involves recently reported materials, as a p-dopant of an organometallic electron-acceptor Copper(II) trifluoromethanesulfonate, that play the role of hole injection layer in order to enhance the performances of the diode.

Comparatively to self-assembled monolayers based optimized structures, the fabricated diodes show higher reproducibility and stability. High rectification ratio for realized pentacene and poly(3-hexylthiophene) diodes up to $10^{6}$ has been achieved. Their high frequency response has been evaluated by performing theoretical simulations. The results predict operating frequencies of $200 \mathrm{MHz}$ and $50 \mathrm{MHz}$ for pentacene and P3HT diode rectifiers respectively, 
with an input oscillating voltage of $2 \mathrm{~V}$ peak-to-peak, promising for RFID device applications or for GSM band energy harvesting in low-cost IoT objects.

Keywords: lithography, coplanar waveguide, diode rectifier, self-assembled monolayer, dopant.

\section{Introduction}

Nowadays, energy harvesting from ambient RF energy has become a topic that attracts a lot of attention, particularly in the framework of Internet-of-Thing autonomous microsystems. In that scope, many works have been carried out with an organic or inorganic rectifier as functional element to harvest electromagnetic waves, for either the accumulated charges to be stored in an on-board microbattery, or for the generated current to be readily used to low-power elementary electrical functions [1-4].

The system that allows this conversion is called a rectenna (rectifying antenna), which is a combination of rectifying circuit and antenna. It is composed by an antenna, an impedance matching circuit, a rectifying component, a DC filter and a load resistance (Fig. 1). Rectifying component is generally a Schottky diode (metal-semiconductor-metal structure) that has two different metal--semiconductor contacts: One is an ohmic contact, and the other is a rectifying contact. The Schottky diodes can offer a low threshold voltage and a low capacitance, parameters that can allow to overcome the problematic of the available low power density. A Schottky diode combined with a coplanar waveguide (CPW) has recently become more and more attractive $[1,2,5]$, since it allows direct injection of the RF power into the rectifier without the insertion of a matching circuit.

A CPW is a kind of planar transmission line used for transmitting microwave signals. It consists of a median metallic strip as a conductor placed between two grounds electrodes. This system has been widely fabricated in case of inorganic diode rectifiers from GaAs [1, 6] or IGZO [7], by employing photolithographic processes which make the alignment of the different active 
layer difficult if we use a mechanical mask. In fact, the gap between the ground and signal need to be controlled in order to maximize the frequency response of the diode. This gap is about some hundreds of $\mu \mathrm{m}$ which makes the alignment difficult with mechanical mask. Another problem is that the active layer can be damaged with le last step of alignment of the ground electrodes.

However, to the best of our knowledge the design of CPW with electron beam lithography in organic semiconductors has not been investigated yet. Since for micro patterning of organic semiconductors, thin films are indeed (brittle - weak) with regard to the solvent induced modifications -solubilization and oxygen plasma etching frequently used in the photolithography process. In the literature, some processes have been developed in the case of Pentacene thin film transistors. By means of three layer lithographic process of polyvinyl alcohol (PVA) that serves as a protective layer for pentacene, Poly (metylmethacrylate) (PMMA) and ammonium dichromate (ADC), Kuo et al [8] have fabricated top contacts on a thin film layer of pentacene. Associating PVA and SU-8 photoresist, Fan et al [9] have created top contact pentacene based organic thin film transistor with patterning pentacene channel layer and source/drain metal electrodes. The lift-off process, was performed in deionized water following by baking in a vacuum oven to remove any residual water. While this process is available in case of pentacene, it cannot be generated for all the organic semiconductors that not resist to water or to the solvents used to prepare the solution of PVA and SU8.

In case of electrochromic displays, micro patterning of PEDOT: PSS has been widely investigated in the literature [10-13] by means of an insulating layer of Parylene C lift-off method. It's a soft process where parylene serves as a mechanical mask for patterning PEDOT:PSS, this by employing a plasma oxygen etching. The particularity of this process is that it does not allow to damage the organic layer with any physical stress (mechanic, pressure, temperature, light), nor contaminate its surface not its bulk with a chemical agent, as it will be 
deposited at the end of the process, and by a peel off of parylene, the PEDOT:PSS is patterned. However, to the best of our knowledge, this technique has not been investigated yet to pattern stacks of organic materials and metals, particularly needed for diode rectifiers or coplanar waveguides where several layers must be structured. In this paper, this process will be developed to pattern both semiconducting organic active layer and metal contacts to design an organic diode rectifier with coplanar waveguide access.

Interface engineering between electrode contacts and active layer is very important in the case of diode rectifiers. In fact, to have good electrical performances as high rectification ratio and low turn on voltage, it is necessary to have Schottky and ohmic contacts on both sides of the active layer. This can be achieved by a judicious choice of the nature and electrical properties of the metals used as anode and cathode, especially their work function value in regards of the HUMO and LUMO of the organic thin layer semiconductor. In order to enhance carriers injections and extend ohmic contact, some solutions have been explored in literature such as injections layers [14-16] or self assembled monolayers (SAMs) [17-19].

SAMs in metal surfaces by fluorinated thiols molecules have been used in a wide variety of applications, since they allow to improve semiconductor growth and morphology as well [20-22], in addition of promoting better charge injection at the semiconductor's interface with electrodes for energetic reasons $[17,19,23]$.

Different injection layers have been reported in literature in case of organic diode rectifiers such as PEDOT: PSS [14, 24], $\mathrm{MoO}_{3}[16,25], \mathrm{WO}_{3}$ [26]. In this report, we use a new hole injection layer for P3HT diode rectifier, that we have developed recently [27] as a new pdoped layer for P3HT that leads to high electrical conductivity.

In this study, a design of CPW device suitable for RF energy harvesting applications using electron beam lithography is presented. This process has been validated for organic diode rectifiers with two categories of materials: deposited in vacuum (pentacene) and solution 
process (P3HT). Electrical characterization of the fabricated diode shows the good rectification ratio up to $10^{6}$ and a very good reproducibility. A performance that has been achieved by enhancing the injection into the active layer employing an injection layer of a P3HT doped with an organometallic electron-acceptor Copper (II) trifluoromethanesulfonate, $\left(\mathrm{Cu}(\mathrm{OTf})_{2}\right)_{\text {) and a }}$ self-assembled monolayer of PFBT. The frequency response of the diode has been also evaluated.

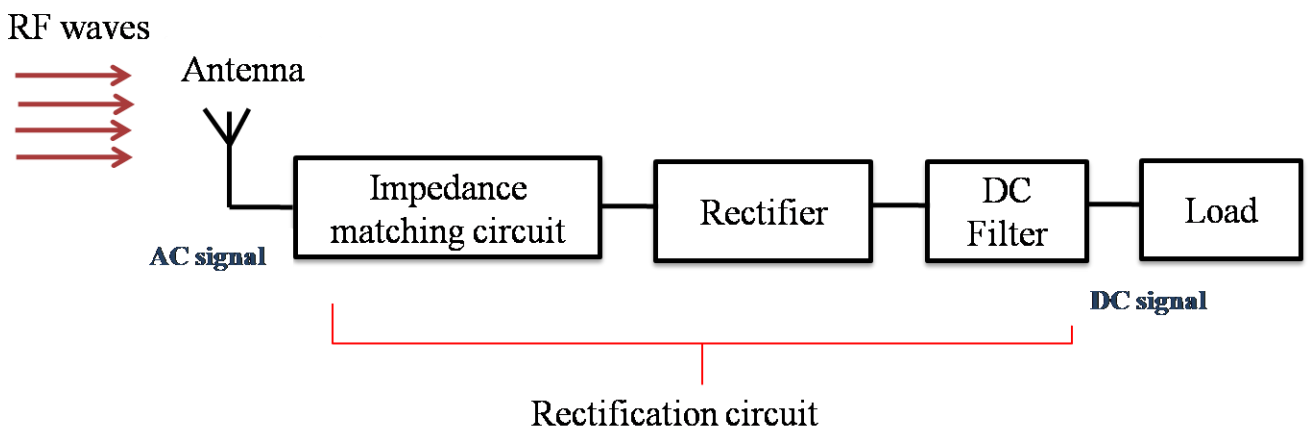

Fig. 1. Schematic of rectenna structure.

\section{Experimental part}

The diode rectifier has been fabricated by "PPEBL" parylene patterning electron beam lithography with a process adapted for the first time for this kind of device. This process has been in part adapted from previous methods reported in the case of electrochromic displays [913]. As showed in (Fig. 2) the process consists of three electron beam lithography steps. After cleaning the substrate which is an n-type $\mathrm{Si}$ substrate with a $200 \mathrm{~nm}$ thermally grown $\mathrm{SiO}_{2}$, we have done the $1^{\text {st }}$ lithography in order to pattern gold electrodes that will serve as a signal input (S) in coplanar waveguide structure, using a resist of Ethylene-methyl acrylate-glycidyl methacrylate (780 nm of COPO 13\%) and poly (methyl methacrylate) (63 nm of PMMA). The resists are then exposed to the electron beam using an EBPG 5000plus masker equipment, and then developed using Methyl isobutyl ketone (MIBK): isopropanol (1:2). This is followed by the deposition of $30 \mathrm{~nm}$ of titanium as adhesion layer and the evaporation of $400 \mathrm{~nm}$ of gold. The lift-off is performed by immersing the sample in acetone. 


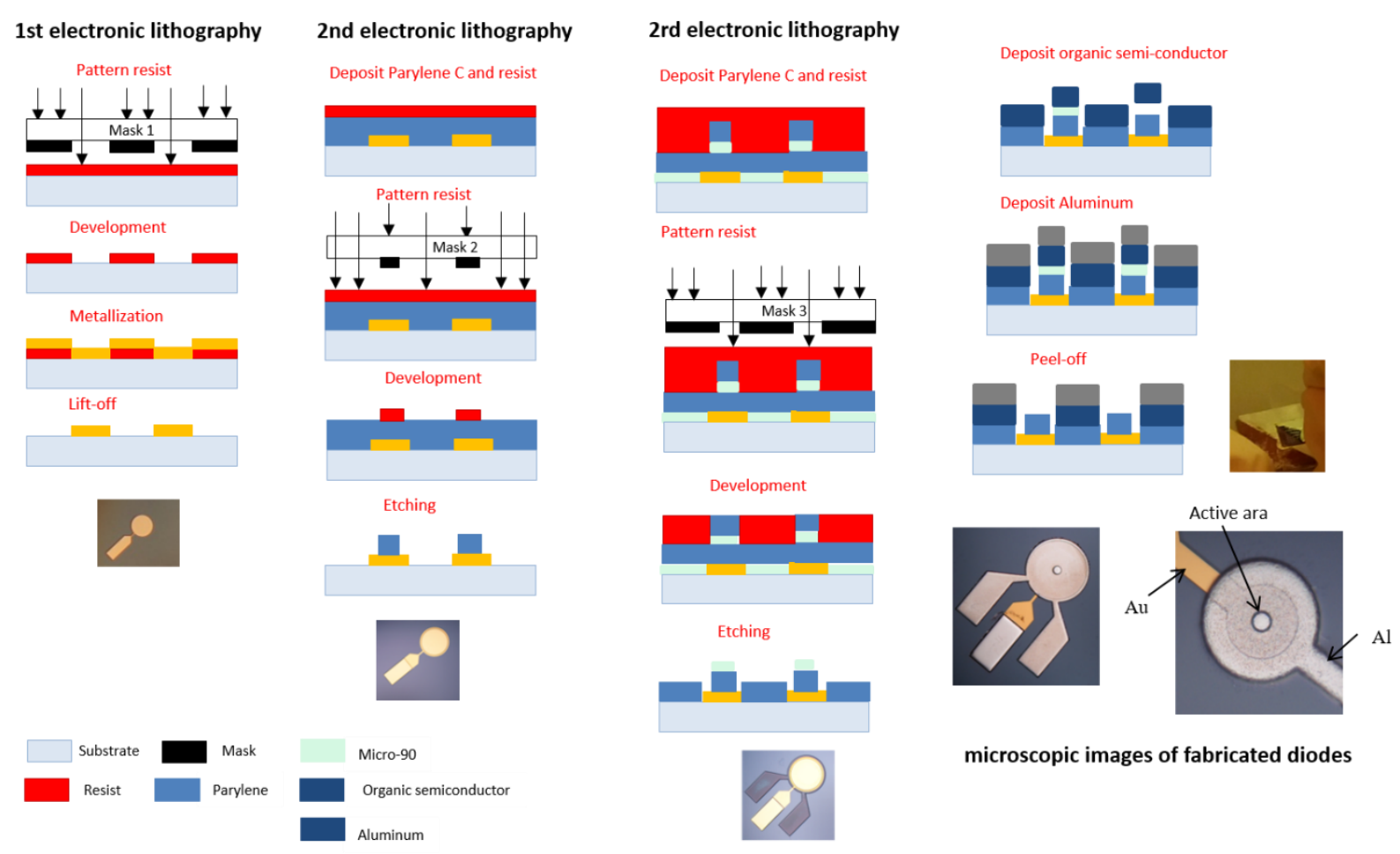

Fig. 2. Scheme of the fabrication process.

The $2^{\text {nd }}$ exposure to the electron beam is performed in order to pattern the active surface area. First, the $\mathrm{SiO}_{2}$ was functionalized with 3-(trimethoxysilyl) propyl methacrylate as an adhesion promoter, for the first parylene $\mathrm{C}(2 \mu \mathrm{m})$ coating on the substrate. Then the device was patterned by electron beam lithography using $2.7 \mu \mathrm{m}$ of AZ40XT photoresist and AZ400K: deionized water developers (2:1), while openings are made with a dry etching process by employing Reactive Ion Etching RIE with an $\mathrm{O}_{2}$ plasma. The $3^{\text {rd }}$ lithography was performed in order to pattern the ground electrodes. First, a surfactant (2\% v/v Micro-90 in deionized water) was deposited on top of the substrate by spin-coating, acting as an anti-adhesive for the second parylene C film. E-beam lithography and dry etching processes were then performed with similar conditions as the $2^{\text {nd }}$ lithographic step. After performing this last electron beam exposure, active layer and $120 \mathrm{~nm}$ of Aluminum layer acting as cathode were deposited by vacuum evaporation. For the active layer, two types of organic semiconductors have been tested in this process: $100 \mathrm{~nm}$ of pentacene deposited in vacuum and $70 \mathrm{~nm}$ of P3HT deposited with a spin coater. Finally, the underlying parylene $\mathrm{C}$ layer is peeled off leaving behind the organic 
diode rectifier in coplanar waveguide structure as depicted in (Fig. 2). Diode rectifier with a different area range from $510^{-7} \mathrm{~cm}^{2}$ to $310^{-4} \mathrm{~cm}^{2}$ has been fabricated.

Electrical measurements were performed in a nitrogen filled glove box $(\mathrm{O} 2$ and $\mathrm{H} 2 \mathrm{O}<$ $0.1 \mathrm{ppm}$ ) by using a microprobe station attached with an Agilent 4156C parameter analyzer. The forward biasing is corresponding to a positive voltage at the Au electrode. Ultraviolet photoelectron spectroscopy (UPS) was performed in an ultra-high vacuum (UHV) system. UPS spectra are recorded by using He I radiation $(21.2 \mathrm{eV})$ line of the discharge lamp. From the UPS spectra, the work function $\Phi$ are determined by applying the following equation:

$\Phi=h v-\left(E_{\text {cutoff }}-E_{f}\right)$, where hv is the energy of incident photons $(21.2 \mathrm{eV}), \mathrm{E}_{\text {cutoff }}$ is the high binding energy measured on UPS spectra and $\mathrm{E}_{\mathrm{f}}$ is the fermi level position.

\section{Results and discussion}

\section{$\underline{\text { 3-1- Organic diode rectifier with P3HT }}$}

In order to enhance charge injection in diode rectifier based P3HT, we have used a hole injection layer of p-doped P3HT with a thickness of $40 \mathrm{~nm}$ that we assessed the concentrationdependent conductivity previously [27]. A series of solution were prepared containing different molar fraction ratio of dopant. In this paper, we have used the fraction ratio that has lead to the highest electrical conductivity of $21 \mathrm{~S} / \mathrm{cm}$. Current-density-Voltage (J-V) characteristics of P3HT diode rectifier with and without hole injection layer with the organometallic electronacceptor $\mathrm{Cu}(\mathrm{OTF})_{2}$ are shown in (Fig. 3a). This figure reveals a very good reproducibility for diode fabricated through this lithographic process. 

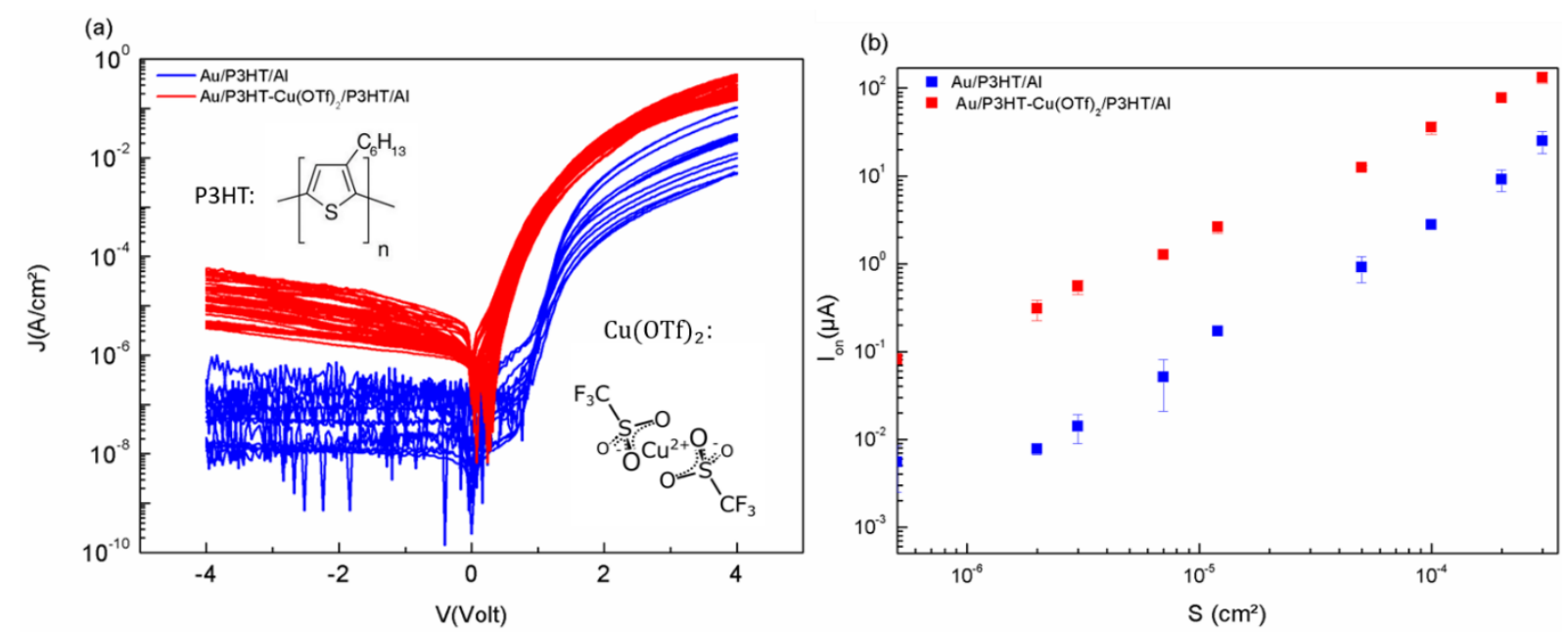

Fig. 3. (a) Electrical characteristics of $\mathrm{P} 3 \mathrm{HT}$ based organic diode rectifier ( 55 diodes), (b) Statistical of lon current.

As shown in (Fig. 3b), a strong enhancement in On current is obtained with the doping layer of $\mathrm{Cu}(\mathrm{OTf})_{2}$. The "On" current is up to $160 \mathrm{~A}$ at $4 \mathrm{~V}$ for the diode with this injection layer, while it's about 30A without.

High rectification ratio up to $10^{5}$ was measured for this structure. This improvement can be attributed to the strong doping of $\mathrm{Cu}(\mathrm{OTF})_{2}$ on $\mathrm{P} 3 \mathrm{HT}$ resulting from the energy barrier lowering on the hole injection side, while it preserves the built-in voltage due the presence of an internal electric field induced by the p-doped/undoped semiconductor junction. Affinity values up to $5.2 \mathrm{eV}$ [28-29] can be obtained, which leads to a lower injection for holes.

\section{3-2- Organic diode rectifier with pentacene}

To extend the applicability of the process to small molecules, Current-density-Voltage $(\mathrm{J}-\mathrm{V})$ characteristics of Pentacene diode rectifier with and without PFBT layer are shown by (Fig. 4). for different surface areas. The current density is up to $0.1 \mathrm{~A} / \mathrm{cm}^{2}$ at $4 \mathrm{~V}$ for the diode with PFBT one or two orders of magnitude higher than the diode without PFBT, and a high rectification ratio up to $10^{6}$ was measured.

These performances can be attributed to a reduction of injection barrier for holes induced by PFBT layer [19]. To verify this hypothesis, UPS spectroscopy has been performed on bare gold and bare gold treated with PFBT as shown by (Fig. 5). From this spectra the work function 
of bare gold and PFBT modified gold are respectively $4.56 \mathrm{eV}$ and $5.1 \mathrm{eV}$, which confirm that the PFBT layer increases the work function of gold. From the energy band diagram (Fig. 5b), we can see that with the PFBT modification, the hole injection barrier is lowered to a value of $0.1 \mathrm{eV}$ (the value of HOMO and LUMO of Pentacene are taken from ref [19]). This confirms, the reduction of barrier injection of holes with PFBT, similar to previous reports [19] which explain the increase of the On current with PFBT modification.

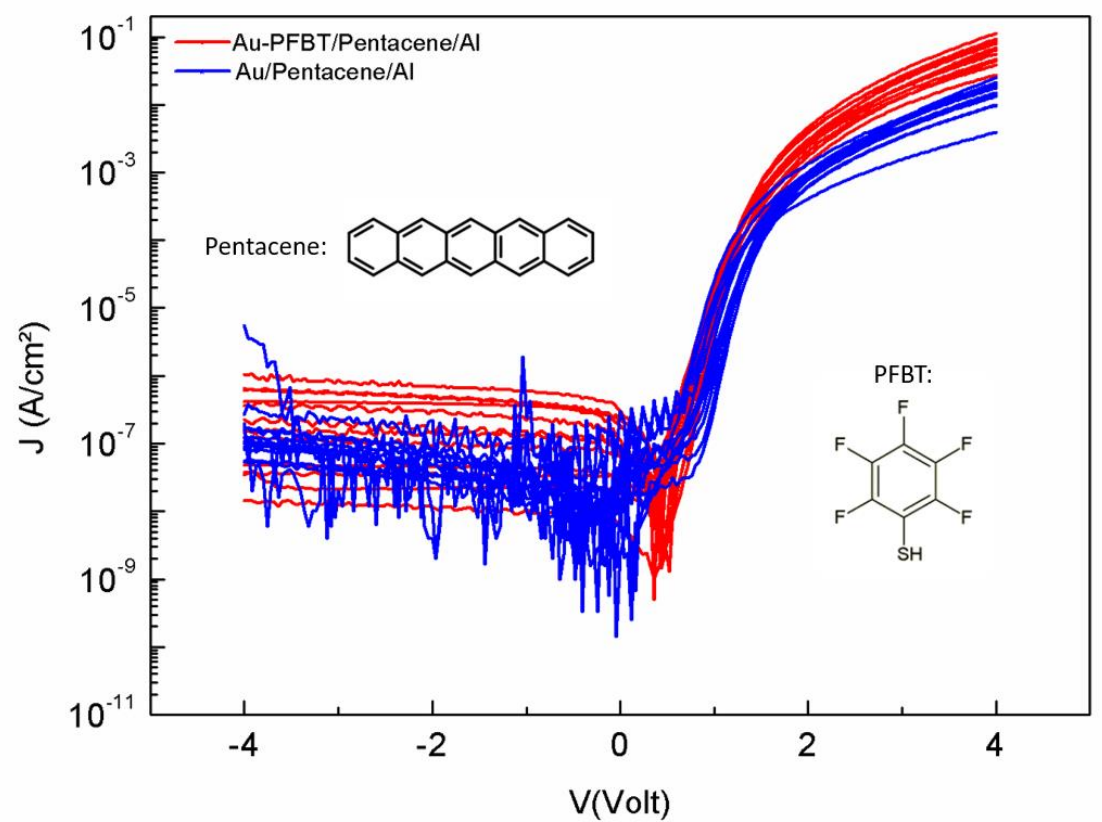

Fig. 4. Electrical characteristics of Pentacene based organic diode rectifier.

The electrical characterization of the diode shows a very good reproducibility through this lithography process. However, we can observe that characteristics with PFBT have less noise for the same "off" current level. In fact, and as has been reported in the literature, PFBT modification leads to a change in the semiconductor film morphology and orientation. The effect of PFBT on the arrangement of organic semiconductor has been studied in the literature by different techniques. From the ratio between short and long axis vibrations in Raman spectra, Kang and coworkers[19], have deduced that in the case of untreated gold this ratio is very low which means that the Pentacene molecules are lying horizontally in the plane of the substrate, while treatment with PFBT increases this ratio to more than 7, indicating that the Pentacene 
molecules are standing more upright, the same result was investigated by Chiodi and coworkers [30], this standing-up molecular geometry is demonstrated to be beneficial in term of the hole mobility improvement[19].

(a)

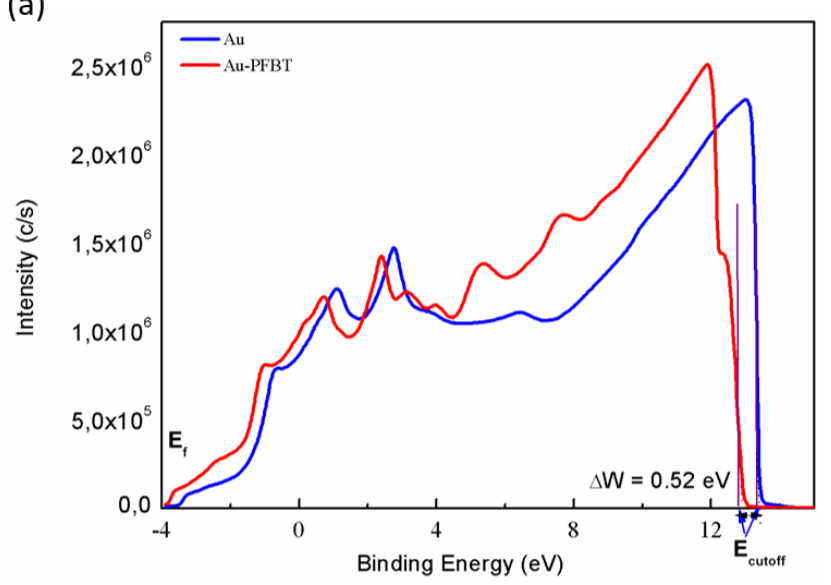

(b)

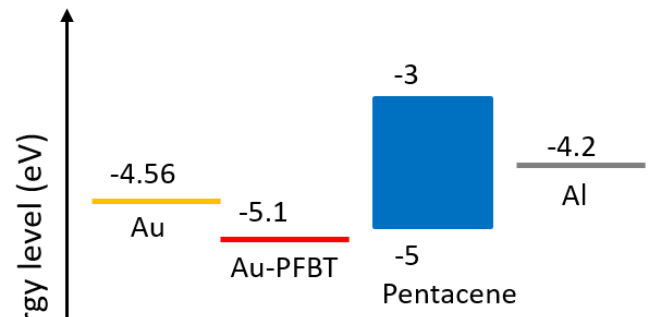

Fig. 5. (a) UPS spectra of bare gold and PFBT-modified gold, (b) Energy band diagram of the device.

\section{3-3- Frequency response of diode}

The frequency response of the fabricated diode rectifier was evaluated by simulation using the basic circuit rectifier shown in the inset of (Fig. 7). This circuit is composed by a function generator, which provides the ac input signal for various frequencies, the diode rectifier and a load capacitance. (Fig. 7) represents the output voltage versus the frequency variation when applied an input voltage of $2 \mathrm{~V}$ peak-to-peak, for Pentacene and P3HT based active layer. The maximum frequency response for both diode has been estimated as a function of the turn on voltage, series resistance and capacitance of the diode: parameters that have been extracted experimentally. Impedance spectroscopy measurement using the Agilent 4294 A impedance analyzer has been performed to extract the series resistance and the capacitance of the diode. As seen by figure 6, theses parameters can be extracted from the Nyquist plot as follow [31]: the minimum value of real $(\mathrm{Z})$ is the value of series resistance and the maximum value of $\operatorname{Im}(Z)$ corresponds to $(\omega=1 / R C)$. Following this method, series resistance is about 800 
$\Omega$ and $1 \mathrm{k} \Omega$ respectively for Pentacene and P3HT diode rectifier. The capacitance is $3.5 \mathrm{pF}$ for Pentacene and $3.2 \mathrm{pF}$ for P3HT diode rectifier.

(a)

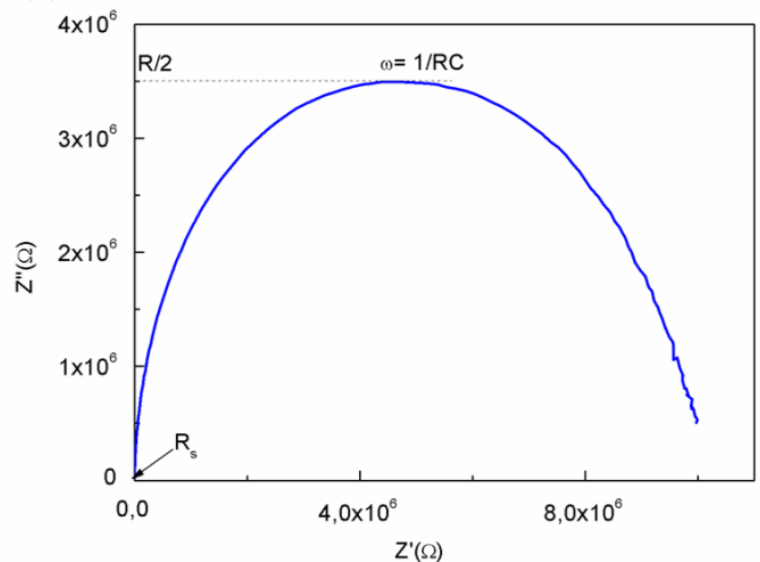

(b)

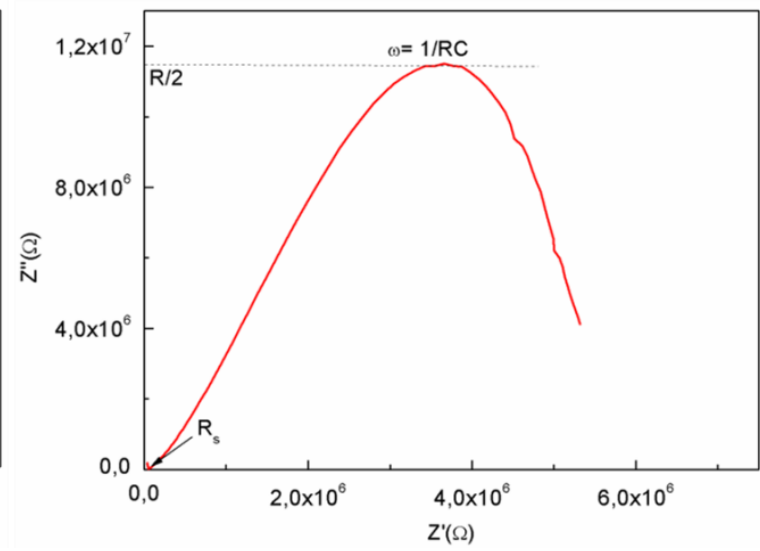

Fig. 6. Nyquist plot for: (a) Pentencene, and (b) P3HT diode rectifier.

For pentacene diode rectifier as shown by (Fig. 7), and under a $50 \mathrm{MHz}-2 \mathrm{~V}$ peak-to-peak oscillating input signal, an output DC voltage of $1.12 \mathrm{~V}$ was obtained, value that decreases to reach a DC output voltage of 0.1 when the input frequency increases to $200 \mathrm{MHz}$. For P3HT diode rectifier, $1.5 \mathrm{~V}$ output voltage can be reached for $1 \mathrm{MHz}$ frequency and $0.6 \mathrm{~V}$ for $50 \mathrm{MHz}$. To use our organic rectification diode in a rectenna for the construction of an energy harvesting system in the GSM frequency bands, the organic diode should be able to work at more than 900 MHz. However, the simulation of the operating frequency of the device demonstrates a low frequency response that can be related to the series resistance of the diodes that is still high (about $800 \Omega$ for pentacene and $1 \mathrm{k} \Omega$ for P3HT). Therefore and at this level, the results rather suggest that both of the proposed diodes show promise for use as rectifiers in radio frequency identification (RFID) tags operating at $13.56 \mathrm{MHz}$ instead of higher RF applications. 


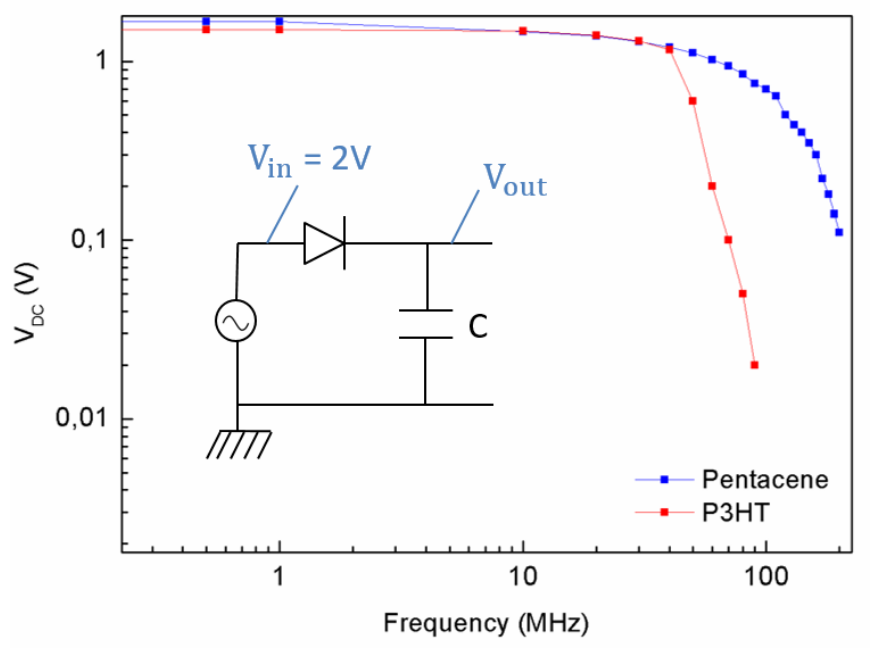

Fig. 7. Output voltage as a function of input frequency for $\mathrm{P} 3 \mathrm{HT}$ and pentacene diode rectifier.

\section{Conclusion}

In this work, a new process to fabricate a diode rectifier in a coplanar waveguide structure has been demonstrated. This process based on electron beam lithography in organic materials can be used in all types of organic semi-conductors deposited in vacuum or in solution. Reproducibility and stability of this process have been tested for Pentacene and P3HT organic diode rectifier. High rectification ratio up to $10^{6}$ has been achieved for both diodes through tuning the work function of gold and enhancing the injection of holes in the active layer, by means of holes injection layers with p-dopant and self-assembled assembled monolayers.

To demonstrate the use of diode in rectifier circuits, its frequency response has been evaluated by simulation. The first results indicate that operation frequency of $200 \mathrm{MHz}$ and $50 \mathrm{MHz}$ can be achieved respectively for Pentacene diode rectifier and P3HT diode rectifier with an input oscillating voltage of $2 \mathrm{~V}$.

These performances are sufficient for applications in RFID or NFC (Near Field Communication) systems around 13,56 MHz. For energy harvesting applications at higher frequencies: (890-1400MHz GSM frequency bands) or (2.4-5GHz WIFI frequency bands) organic devices must reach higher performances. 
The operating frequencies being strongly related to the resistance of the organic materials used and to the mobility of their charge carriers (in this study we used materials with mobilities < $0.3 \mathrm{~cm} 2 / \mathrm{Vs})$. Higher experimental values in frequency can be obtained due to the possible presence of crystallites parts of high mobility in the material which are not supported by the simulation model. On another level, an optimization process can be lunched in direction of the resistance and capacity of the organic layers used.

Other solution consists of the of polymer/small molecule blend. This method developed by Paterson et al is based on the incorporation of the p-dopant and the growth of a vertically phaseseparated film microstructure. This method has made it possible to achieve mobilities as high as $13 \mathrm{~cm} 2 / \mathrm{V} . \mathrm{s}$ [32]. These blends can increase the frequency cut off by more than one order of magnitude. 


\section{Acknowledgements}

This work was supported by European Project Interreg Luminoptex and ANR

Context project. We thank the French National Nanofabrication Network RENATECH for financial support of the IEMN cleanroom, and Ludovic Burgnies for his recommendation for the design of the CPW structure. 


\section{References}

[1] F. Mustafa, N. Parimon, A-M. Hashim, S- F. Abd Rahman, A- R. Abdul Rahman, M. Nizam Osman, RF-DC power conversion of Schottky diode fabricated on AlGaAs/GaAs heterostructure for on-chip rectenna device application in nanosystems, Microsystem Technologies. 16 (2010) 1713-1717. 10.3923/jas.2010.2041.2046.

[2] A-M. Hashim, F. Mustafa, S-F-A. Rahman, A-R-A . Rahman, Dual-functional on-chip AlGaAs/GaAs Schottky diode for RF power detection and low-power rectenna applications, Sensors. 11 (2011) 8127-42. 10.3390/s110808127 .

[3] J. Semple, D-G. Georgiadou, G. Wyatt-Moon, G. Gelinck, T-D. Anthopoulos, Flexible diodes for radio frequency (RF) electronics: a materials perspective, Semiconductor Science and Technology. 32 (2017) 123002 (1-45). https://doi.org/10.1088/1361-6641/aa89ce.

[4] S- G. Higgins, T. Agostinelli, S. Markham, R. Whiteman, H. Sirringhaus, Organic Diode Rectifiers Based on a High-Performance Conjugated Polymer for a Near-Field EnergyHarvesting Circuit, Advanced materials. $46 \quad$ (2017) 1703782 (1-6). https://doi.org/10.1002/adma.201703782.

[5] S-A. Banu, A. Vishwapriya , R. Yogamathi , A-V. Meenakshi, S-P-K. Babu, Analysis and comparison of a coplanar waveguide and micro strip based rectenna, Materials science. 2 (2012) 8-12. 10.9756/BIJRCE.2018.

[6] N. Parimon, R-R. Porle, M. Mamat, Fabrication process of n-AlGaAs/GaAs Schottky diodes for on-chip direct integrated with dipole antenna, Universal Journal of Electrical and Electronic Engineering. 3 (2015) 81-4. 10.13189/ujeee.2015.030302.

[7] J. Zhang, Y. Li, B. Zhang, H. Wang, Q. Xin, A. Song, Flexible indium-gallium-zinc-oxide Schottky diode operating beyond $2.45 \mathrm{GHz}$, Nature Communications. 6 (2015) 7561. 10.1038/ncomms8561.

[8]C-C. Kuo, T-N. Jackson, Directly lithographic top contacts for pentacene organic thin-film transistors, Conference Digest [Includes"Late News Papers"volume] Device Research Conference. 1 (2004) 85-6. 10.1109/DRC.2004.1367795.

[9] C-L. Fan, W-C. Lin, C-C. Lee, Y-Z. Lin, B-R. Huang, Fabrication of top-contact pentacenebased organic thin-film transistors with short channels using two-step SU8/poly(vinyl alcohol) lift-off photolithography process, Jpn J Appl Phys. 55 (2016) 026502. 10.7567/JJAP.55.026502. [10] S. Takamatsu, T. Takahata, K. Matsumoto, I. Shimoyama, Micro-patterning of a conductive polymer and an insulation polymer using the parylene lift-off method for electrochromic displays, J Micromech Microeng. 21 (2011) 075021. https://doi.org/10.1088/09601317/21/7/075021.

[11] M. Sessolo, D. Khodagholy, J. Rivnay, F. Maddalena, M. Gleyzes, E. Steidl, B. Buisson, G-G. Malliaras, Easy-to-fabricate conducting polymer microelectrode arrays, Adv Mater Weinheim. 25 (2013) 2135-9. https://doi.org/10.1002/adma.201204322.

[12] S. Pecqueur, S. Lenfant, D. Guerin, F. Alibart, D. Vuillaume, Concentric-Electrode Organic Electrochemical Transistors: Case study for selective hydrazine sensing, Sensors. 17 (2017) 570. https://doi.org/10.3390/s17030570. 
[13] S. Pecqueur, D. Guerin, D. Vuillaume, F. Alibart, Cation discrimination in organic electrochemical transistors by dual frequency sensing , Organic Electronics. 57 (2018) 232-8. https://doi.org/10.1016/j.orgel.2018.03.020.

[14] C. Kang, S. Kim, Y. Hong, C. Lee , Frequency analysis on poly(3-hexylthiophene) rectifier using impedance spectroscopy, Thin Solid Films. 518 (2009) 889-92. 10.1016/j.tsf.2009.07.110.

[15] D-S. Song, J. Roch, C. Lee, D. Young Shin, J-H. Bae, H. Kim, Hole injection in N-type organic semiconductors by tuning metal work function with functional self-assembled monolayers, Journal of Nanoscience and Nanotechnology. 17 (2017) 3378-81. 10.1166/jnn.2017.14036.

[16] C. Kang, Y. Hong, C. Lee, Frequency performance optimization of flexible pentacene rectifier by varying the thickness of active layer, Jpn J Appl Phys. 49 (2010) 05EB07. 10.1143/JJAP.49.05EB07.

[17] J-P. Hong, A-Y. Park, S. Lee, J. Kang, N. Shin, D-Y .Yoon, Tuning of Ag work functions by self-assembled monolayers of aromatic thiols for an efficient hole injection for solution processed triisopropylsilylethynyl pentacene organic thin film transistors, Applied Physics Letters 92 (2008) 143311. https://doi.org/10.1063/1.2907691.

[18] O. Fenwick, C-V. Dyck, K. Murugavel, D. Cornil, F. Reinders, S. Haar, M. Mayor, J. Cornil, P. Samori, modulating the charge injection in organic field-effect transistors: fluorinated oligophenyl self-assembled monolayers for high work function electrodes, J Mater Chem C. 3 (2015) 3007-15. 10.1039/C5TC00243E.

[19] C .Kang, J. Wade, S. Yun, J. Lim, H. Cho, J. Roh, H .Lee, S. Nam, D-C. Bradley, Ji-S. Kim, C. Lee, $1 \mathrm{GHz}$ Pentacene diode rectifiers enabled by controlled film deposition on SAM-treated Au anodes, Advanced Electronic Materials. $2 \quad$ (2016) 1500282. https://doi.org/10.1002/aelm.201500282.

[20] D-J. Gundlach, J-E. Royer, S-K .Park, S .Subramanian, O-D. Jurchescu, B-H. Hamadani, A- J. Moad, R- J. Kline, L- C. Teague, O. Kirillov, C-A. Richter, J- G. Kushmerick, L- J. Richter, S- R. Parkin, T-N. Jackson \& J-E. Anthony, Contact-induced crystallinity for high performance soluble acene-based transistors and circuits. Nature Materials. 7 (2008) 21621. 10.1038/nmat2122.

[21] J-W. Ward, M-A. Loth, R-J. Kline RJ, M. Coll, C .Ocal, J-E. Anthony, O-D. Jurchescu, Tailored interfaces for self-patterning organic thin-film transistors. J Mater Chem. 22 (2012) 19047-53. https://doi.org/10.1039/C2JM33974A.

[22] R-J. Kline, S-D. Hudson, X. Zhang, D-J. Gundlach, A-J. Moad, O-D. Jurchescu, T- N. Jackson, S. Subramanian, J-E. Anthony, M- F. Toney, L- J. Richter, Controlling the Microstructure of Solution-Processable Small Molecules in Thin-Film Transistors through Substrate Chemistry. Chem Mater. 23 (2011) 1194-203.

https://doi.org/10.1021/cm102834m.

[23] B-de. Boer, A . Hadipour, R. Foekema, T-Van. Woudenbergh, M-M. Mandoc, V-D. Mihailetchi, P-W-M. Blom, Tuning of metal work functions with self-assembled monolayers. Proc. SPIE, Organic Optoelectronics and Photonics. 5464 (2004) 18-26.

https://doi.org/10.1117/12.546046. 
[24] S. Steudel, De. Vusser, K. Myny, M. Lenes, J. Genoe, P. Heremans, Comparison of organic diode structures regarding high-frequency rectification behavior in radio-frequency identification tags. Journal of Applied Physics. 99 (2006) 114519.

https://doi.org/10.1063/1.2202243.

[25] S-G. Higgins, T. Agostinelli, S. Markham, R. Whiteman, H. Sirringhaus, Organic Diode Rectifiers Based on a High-Performance Conjugated Polymer for a Near-Field Energy Harvesting Circuit. Advanced Materials. 29 (2017) 1703782.

https://doi.org/10.1002/adma.201703782.

[26] D. Im, H. Moon, M. Shin, J. Kim, S. Yoo, Towards Gigahertz Operation: Ultrafast Low Turn-on Organic Diodes and Rectifiers Based on 660 and Tungsten Oxide. Advanced Materials. 23 (2011) 644-8. 10.1002/adma.201002246.

[27] K. Ferchichi, R. Bourguiga, K. Lmimouni, S. Pecqueur, Concentration-control in all solution processed semiconducting polymer doping and high conductivity performances. Synthetic Metals. 262 (2020) 116352. https://doi.org/10.1016/j.synthmet.2020.116352. [28] H. Kleemann, S. Schumann, U. Jorges, F. Ellinger, K. Leo, B. Lussem, Organic pin diodes approaching ultra-high-frequencies. Organic Electronics. 13 (2012) 1114-1120. https://doi.org/10.1016/j.orgel.2012.03.011.

[29] W. Gao, A. Kahn, Controlled p-doping of zinc phthalocyanine by coevaporation with tetrafluorotetracyanoquinodimethane : A direct and inverse photoemission study. Appl Phys Lett. 79 (2001) 4040-4042. https://doi.org/10.1063/1.1424067.

[30] M. Chiodi, L. Gavioli, M. Beccari, V. Di Castro, A. Cossaro, L. Floreano, A. Morgante, A. Kanjilal, C. Mariani, M. Grazia Betti, Interaction strength and molecular orientation of a single layer of pentacene in organic-metal interface and organic-organic heterostructure. Physical Review B. 77 (2008) 115321. 10.1103/PhysRevB.77.115321.

[31]C-H. Kim, O. Yaghmazadeh, D. Tondelier, Y-B. Jeong, Y. Bonnassieux, G. Horowitz, Capacitive behavior of pentacene-based diodes: Quasistatic dielectric constant and dielectric strength. Journal of Applied Physics. 109 (2011) 083710. https://doi.org/10.1063/1.3574661. [32]A-F. Paterson, N-D. Treat, W. Zhang, Z. Fei, G. W-Moon, H. Faber, G. Vourlias, P-A. Patsalas, O. Solomeshch, N. Tessler, M. Heeney, T-D. Anthopoulos, Small molecule/polymer blend organic transistors with hole mobility exceeding $13 \mathrm{~cm}(2) \mathrm{V}(-1) \mathrm{s}(-1)$. Adv.Mater. 28 (2016) 7791-8. 10.1002/adma.201601075. 